Research Paper

\title{
Diagnostic accuracy of frozen section analysis of borderline ovarian tumors: a meta-analysis with emphasis on misdiagnosis factors
}

\author{
Zhen Huang1,2,3,\#, Li Li1,\#, ChengCheng Li1,2, Samuel Ngaujah'1,2, Shu Yao1,2, Ran Chu1,2, Lin Xie1,2,

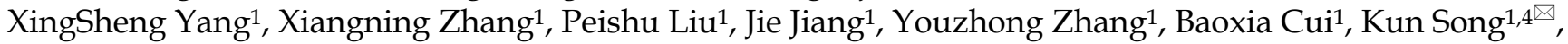 \\ Beihua Kong ${ }^{1,4}$ \\ 1. Department of Obstetrics and Gynecology, Qilu Hospital of Shandong University, Ji'nan city, Shandong province, China. \\ 2. School of Medicine, Shandong University, Ji'nan city, Shandong province, China. \\ 3. Ganzhou maternity \& child health hospital, Jiangxi province, China \\ 4. Gynecology oncology key laboratory, Qilu Hospital, Shandong University, Ji'nan city, Shandong province, China. \\ \# Zhen Huang and Li Li contribute equally to this paper. \\ $\square$ Corresponding author: Dr. Kun Song, M.D., Ph.D., Department of Obstetrics and Gynecology, Qilu Hospital of Shandong University, 107 Wenhuaxi Road, \\ Ji'nan city 250012, Shandong Province, P.R. China. Phone: +86-0531-82169551; Fax: +86-0531-86927544; Email: songkun2001226@sdu.edu.cn \\ (c) Ivyspring International Publisher. This is an open access article distributed under the terms of the Creative Commons Attribution (CC BY-NC) license \\ (https://creativecommons.org/licenses/by-nc/4.0/). See http://ivyspring.com/terms for full terms and conditions.
}

Received: 2018.03.05; Accepted: 2018.06.09; Published: 2018.07.16

\begin{abstract}
Objective: First, to evaluate the sensitivity and positive predictive value (PPV) of intra-operative frozen section (FS) diagnosis in borderline ovarian tumors (BOTs), and to explore the factors affecting the diagnostic accuracy. Second, to assess the clinical outcomes of misdiagnosed BOT patients.

Methods: We performed a retrospective study of all patients diagnosed as BOT through FS or paraffin section (PS) at Qilu Hospital between January 2005 and December 2015. Clinical and pathologic data were extracted. Univariate analysis was performed using standard two-sided statistical tests. We also performed a meta-analysis to further validate the findings.

Results: In our retrospective study, 155 patients were included. Agreement between FS and PS diagnosis was observed in $127 / 155$ (81.9\%) patients, yielding a sensitivity of $92.7 \%$ and a PPV of $87.6 \%$. Under-diagnosis and over-diagnosis occurred in 22 cases (14.2\%) and 6 cases (3.9\%), respectively. In our univariate analysis of our retrospective study, tumor size $(p=0.048)$ and surgery approach $(p=0.024)$ were significantly associated with misdiagnosis.

The pooled analysis of 13 studies including 1,577 patients indicated that the accuracy (69.2\%), sensitivity (82.5\%), and PPV (81.1\%) were low; also under-diagnosis (20.2\%) and over-diagnosis (10.5\%) were frequent. The meta-analysis results showed that mucinous histology $(p<0.0001, \mathrm{OR}=2.03[1.47-2.81])$ and unilateral tumors $(p=0.001, O R=2.39[1.41-4.06])$ were associated with the misdiagnosis of BOT. In our retrospective study, there was no statistical significance of clinical outcome such as extent of surgery $(p=0.838)$, recurrence $(p=0.586)$, fertility $(p=0.560)$, death $(p=0.362)$ between misdiagnosed and accurately diagnosed BOT patients.

Conclusions: FS analysis of BOTs has low accuracy, sensitivity, and PPV. Under-diagnosis and over-diagnosis are frequent. Meta-analysis results verify that mucinous histology and unilateral tumors are associated with misdiagnosis of FS. Nevertheless, misdiagnosed patients have a good clinical outcome despite the high frequency of misdiagnosis through FS.
\end{abstract}

Key words: borderline ovarian tumor; frozen section; paraffin section; sensitivity; accuracy

\section{Introduction}

Ovarian tumors are a heterogeneous group of tumors including surface epithelial tumors, germ cell tumors, and sex cord stromal tumors. Borderline ovarian tumors (BOTs) comprise about $15 \%-20 \%$ of all epithelial ovarian malignancies, with an incidence of $1.8-4.8$ per 100,000 women per year [1,2]. Despite 
improvements in imaging techniques and identification of tumor markers, preoperative diagnosis of the malignant potential of ovarian tumors remains unreliable, and intra-operative pathological examination is irreplaceable [3-5]. Preference for frozen section (FS) diagnosis vs. paraffin section (PS) diagnosis of BOT differs from study to study. The sensitivity of FS ranges from $25 \%$ to $92 \%[3,4,6,7]$, and specificity ranges from $60 \%$ to $99 \%$ [3, 4, 6-8]. Several authors have investigated the causes of low accuracy in FS examinations to identify BOTs and have defined various clinic-pathological features for prediction of misdiagnosis [9-16], but there is no consensus. The misdiagnosis by FS has a greater chance of harming patients. Hence, a correct and timely diagnosis of BOT is necessary.

The aims of our study are as follows: (1) to explore the accuracy of FS analysis of BOTs; (2) to determine the factors that affect the accuracy of diagnosis through FS; and (3) to assess the clinical outcomes of misdiagnosed BOT patients. We performed a retrospective study to establish our research aims, and we also performed a literature review and meta-analysis to confirm our research results. Based on our knowledge, this is the first meta-analysis to focus on the misdiagnosis factors of FS in BOTs patients.

\section{Materials and methods}

A retrospective study was performed with the ethical review board approval of Qilu Hospital. We identified all patients diagnosed with BOT through intra-operative FS or PS diagnosis at our institution from January 2005 to December 2015. BOT were classified as serous, mucinous, mixed, endometroid, clear cell, Brenner. Cases were excluded if: (1) there was no FS or PS diagnosis; (2) there were another primary malignancy; or (3) primary surgery was performed in another hospital. Medical records including clinical characteristics, operative reports, pathological and laboratory reports, and chemotherapy records were reviewed, and data were extracted. We also followed up with all patients, consulting about recurrence, death, and fertility outcome.

Fresh specimens were sent for intra-operative examination separated by five minutes, and one senior pathologist with more than five years' experience reported on them within 30 minutes. Another pathologist reported on the paraffin sections. In another word, each case was reported by two different pathologists. The reports of FS and PS were divided into benign, borderline, and malignant. We also collected the information of specific final diagnosis such as micro-invasion, focal carcinoma, epithelial carcinoma, micro papillary and so on. Discrepancies included under-diagnosis, overdiagnosis. The standard type of care regarding BOT in our hospital are followed NCCN guidelines. Patients who desire to maintain their fertility may undergo surgery limited to a unilateral salpingo-oophorectomy (preserving the uterus, contralateral ovary, and contralateral Fallopian tube) with resection of residual disease. If the patient does not desire fertility sparing surgery, standard ovarian cancer debulking surgery and resection of residual disease are recommended.

Statistical analysis was performed using IBM SPSS Statistics 20.0 software. A $p$ value of less than 0.05 was considered statistically significant. Univariate analysis was performed looking at predictors of accuracy on frozen sections which was two-tailed hypothesis. The accuracy, sensitivity, and PPV of each study and the comparison of misdiagnosis factors were calculated using Review Manager 5.3 software.

A comprehensive literature search was performed using Pubmed, PMC, MEDLINE and the Cochrane Library database. The following words and proper combinations were used: "borderline ovarian tumors" (or "low malignant potential") and "frozen section" were combined with the medical subject heading "diagnosis" ("accuracy, sensitivity, and specificity"). The search was limited to human studies and full-length reports. Studies were eligible if they exclusively investigated BOTs and had sufficient numbers to construct $3 \times 3$ tables. Studies on intra-operative FS analysis of ovarian tumors that were stratified to look at BOTs as a subgroup, or without sufficient data to construct $3 \times 3$ tables, were excluded.

Data extraction was conducted independently by two of the authors. All disagreements were resolved by discussion among all authors. For the meta-analysis, the raw and transformed data were calculated, and both fixed-effect and random-effect models were used to estimate the overall proportions. The heterogeneity was evaluated by $Q$ test and $\mathrm{I}^{2}$. The pooled odds ratio (OR) and $95 \%$ confidence intervals (CI) were performed using log-transformed data with the Mantel-Haenszel method. Forest plots were used to visualize the results of the meta-analysis.

\section{Results}

A total of 155 patients were identified in our retrospective study. The median age was 40 years (range13-86 years) and mean CA-125 level at the time of diagnosis was $201.6 \mathrm{U} / \mathrm{ml}$ (range1.39-4918 U/ml). Histologic subtypes included serous in 70 patients $(45.2 \%)$, mucinous in 77 patients $(49.7 \%)$, others in eight patients $(5.1 \%)$. The mean size of tumors was 13 
$\mathrm{cm}$ (range1.9-40.0 $\mathrm{cm}$ ). Mucinous tumors had the largest mean size of $16.6 \mathrm{~cm}$ (range 1.9-40.0cm). Based on the FIGO staging system, 121 patients $(78.1 \%)$ were stage I. A total of 41 patients $(26.5 \%)$ had bilateral lesions.

The comparison between FS and PS diagnosis is shown in Table 1. The overall agreement between FS and PS diagnosis was observed in 127/155 cases $(81.9 \%)$, yielding a sensitivity and a positive predictive value of $92.7 \%$ and $87.6 \%$, respectively. Of note, under-diagnosis was identified in 22 cases $(14.2 \%)$, whereas over-diagnosis was identified in 6 cases $(3.9 \%)$. The discrepancy in cases are as follows: in the under-diagnosis group, 15 cases were borderline through FS/ malignant through PS, and 7 cases were benign through FS/ borderline through PS. In the over-diagnosis group, 3 cases were malignant through FS/ borderline through PS, and 3 cases were borderline through FS/ benign through PS.

Table 1. Comparison of frozen and paraffin section diagnosis for ovarian tumors $(n=155)$

\begin{tabular}{llllll}
\hline \multicolumn{5}{c}{ Paraffin diagnosis } & Total \\
\hline Frozen & Benign & 0 & 7 & 0 & 7 \\
section & Borderline & 3 & $127^{\dagger}$ & $15^{\neq}$ & 145 \\
diagnosis & Balignant & 0 & 3 & 0 & 3 \\
& Total & 3 & 137 & 15 & 155 \\
& & & & & Malignant \\
\end{tabular}

Note: Benign: benign ovarian tumors; Borderline: borderline ovarian tumors; Malignant: malignant ovarian tumors.

${ }^{\dagger}$ : there were 11 patients uncertain-diagnosed as BOT by frozen section, and turned out to be BOT by paraffin diagnosis; ${ }^{\ddagger}$ : there were 3 patients uncertain-diagnosed as BOT by frozen section and turned out to be malignant by paraffin diagnosis.

The relationship between patients' clinical characteristics and misdiagnosis of FS analysis is shown in Table 2. In a univariate analysis, tumor size $(p=0.048)$ and surgery approach $(p=0.024)$ were associated with misdiagnosis of FS analysis, but the patients' age, tumor histology, tumor stage, presence of a bilateral tumor and number of frozen sections were not associated.

In our systematic literature review, 135 studies were initially identified, of which 95 were excluded because reading the titles and abstracts showed that they did not report on the association between FS and PS diagnosis. A total of 28 articles [6-8, 17-32] were excluded because BOTs were not exclusively investigated or were assessed only in subgroup analysis, or data were insufficient to construct $3 \times 3$ tables. Finally, 1,577 cases from 13 primary studies [9-16, 32-35], including our present retrospective study, met the criteria for inclusion and were analyzed. There was no disagreement between the two authors who judged the pre-selected articles. Table 3 shows that overall accuracy was observed in 1,092/1,577 (69.2\%) cases, yielding a sensitivity and a
PPV of $82.5 \%$ and $81.1 \%$, respectively. Under-diagnosis and over-diagnosis were identified in $319(20.2 \%)$ and $166(10.5 \%)$ cases, respectively.

Table 2. Patient characteristics and results of frozen section diagnosis $(n=155)$

\begin{tabular}{|c|c|c|c|c|c|}
\hline \multirow[t]{2}{*}{ variables } & \multicolumn{5}{|c|}{$\begin{array}{l}\text { Frozen diagnosis compared with permanent } \\
\text { diagnosis }\end{array}$} \\
\hline & $\begin{array}{l}\text { Total } \\
(\mathrm{n}=155)\end{array}$ & $\begin{array}{l}\text { Under-diagnosis } \\
(\mathrm{n}=22)\end{array}$ & $\begin{array}{l}\text { Same-diagnosis } \\
(\mathrm{n}=127)\end{array}$ & $\begin{array}{l}\text { Over-diagnosis } \\
(\mathrm{n}=6)\end{array}$ & $p^{*}$ \\
\hline Ages(years) & & & & & 0.693 \\
\hline$<40$ & 86 & 14 & 69 & 3 & \\
\hline$\geq 40$ & 69 & 8 & 58 & 3 & \\
\hline CA-125(U/ml) & & & & & 0.053 \\
\hline$<35$ & 56 & 13 & 41 & 2 & \\
\hline$\geq 35$ & 99 & 9 & 86 & 4 & \\
\hline $\begin{array}{l}\text { Surgery } \\
\text { approach }\end{array}$ & & & & & 0.024 \\
\hline Laparotomy & 115 & 14 & 99 & 2 & \\
\hline Laparoscopy & 40 & 8 & 28 & 4 & \\
\hline Cyst rupture & & & & & 0.459 \\
\hline Yes & 36 & 3 & 32 & 1 & \\
\hline No & 119 & 19 & 95 & 5 & \\
\hline $\begin{array}{l}\text { Tumor } \\
\text { size }(\mathrm{cm})\end{array}$ & & & & & 0.048 \\
\hline$\leq 10$ & 80 & 7 & 68 & 5 & \\
\hline$>10$ & 75 & 15 & 59 & 1 & \\
\hline $\begin{array}{l}\text { Bilateral } \\
\text { disease }\end{array}$ & & & & & 0.280 \\
\hline Yes & 41 & 5 & 36 & 0 & \\
\hline No & 114 & 17 & 91 & 6 & \\
\hline FIGO Stage & & & & & 0.783 \\
\hline I & 121 & 17 & 100 & 4 & \\
\hline II-IV & 34 & 5 & 27 & 2 & \\
\hline Histology & & & & & 0.054 \\
\hline Mucinous & 77 & 16 & 59 & 2 & \\
\hline Other & 78 & 6 & 68 & 4 & \\
\hline $\begin{array}{l}\text { Micro } \\
\text { papillary }\end{array}$ & & & & & 0.267 \\
\hline yes & 10 & 0 & 9 & 1 & \\
\hline no & 145 & 22 & 118 & 5 & \\
\hline Microinvasion & & & & & 0.163 \\
\hline yes & 15 & 0 & 15 & 0 & \\
\hline no & 140 & 22 & 112 & 6 & \\
\hline $\begin{array}{l}\text { Peritoneal } \\
\text { washing }\end{array}$ & & & & & 0.641 \\
\hline yes & 4 & 0 & 4 & 0 & \\
\hline no & 151 & 22 & 123 & 6 & \\
\hline $\begin{array}{l}\text { Invasive } \\
\text { implants }\end{array}$ & & & & & 0.275 \\
\hline yes & 15 & 4 & 11 & 0 & \\
\hline no & 140 & 18 & 116 & 6 & \\
\hline $\begin{array}{l}\text { Noninvasive } \\
\text { implants }\end{array}$ & & & & & 0.231 \\
\hline yes & 15 & 0 & 14 & 1 & \\
\hline no & 140 & 22 & 113 & 5 & \\
\hline Number of FS & & & & & 0.423 \\
\hline$\leq 3$ & 106 & 17 & 84 & 5 & \\
\hline$\geq 4$ & 49 & 5 & 43 & 1 & \\
\hline
\end{tabular}

statistically significant; FS: frozen section

Seven included studies stated the factors that affect the accuracy of FS of BOTs. Characteristics of included studies for meta-analysis are shown in Table 4. We performed a meta-analysis to validate the findings. We found that mucinous histology $(p<$ 0.0001, OR=2.03[1.47-2.81]) and unilateral tumors $(p=0.001, \mathrm{OR}=2.39[1.41-4.06])$ were associated with the misdiagnosis of BOT, while CA- $125 \quad(p=0.05$, 
$\mathrm{OR}=0.55[0.30-1.01])$ and surgery approach $(p=0.50$, $\mathrm{OR}=1.34[0.57-3.11]$ ) were not significant statistically. The outcome of the meta-analysis is shown in Figure 1. Measurement of tumor diameters could not be performed by meta-analysis due to different cutoff values in the included studies.

Uncertain FS diagnoses were reported for 14 patients, such as "not excluded", "not ruled out", "favor", and "at least", of which 11 patients were proven to have BOT and 3 patients were eventually proved to have a malignancy. In Table 2 and Table 5, these 11 patients were grouped as same-diagnosis, another 3 patients were grouped as under-diagnosis. Only 2 of 11 patients with BOT had fertility sparing surgery (FSS), and the other 12 patients had radical surgery. Two patients received chemotherapy, of whom one had an advanced stage of FIGO IV and another had a carcinoma diagnosed through PS. Both of them had a good prognosis without recurrent cancer or death.

Table 3. Characteristics of included studies

\begin{tabular}{|c|c|c|c|c|c|c|c|c|c|c|c|c|}
\hline Study & country & total & $\mathrm{TP}$ & $\mathrm{FP}$ & $\mathrm{FN}$ & $\mathrm{TN}$ & $\mathrm{A}(\%)$ & Sen $(\%)$ & PPV (\%) & under & over & same \\
\hline Bozdag H et al.2016 & Turkey & 36 & 28 & 2 & 6 & NA & 77.8 & 82.4 & 93.3 & 8 & 0 & 28 \\
\hline Basaran D et al.2014 & Turkey & 59 & 37 & 7 & 15 & NA & 62.7 & 71.2 & 84.1 & 18 & 4 & 37 \\
\hline Song T et al.2011 & Korea & 354 & 228 & 40 & 86 & NA & 64.4 & 72.6 & 85.1 & 108 & 18 & 228 \\
\hline Shih KK et al.2011 & USA & 120 & 104 & 16 & 0 & NA & 86.7 & NA & 86.7 & 1 & 15 & 104 \\
\hline Li M et al.2009 & China & 73 & 55 & 10 & 8 & NA & 75.3 & 87.3 & 84.6 & 18 & 0 & 55 \\
\hline Kim K et al.2009 & South Korea & 181 & 109 & 72 & 0 & NA & 60.2 & NA & 60.2 & 11 & 61 & 109 \\
\hline Kim JH et al.2009 & Korea & 101 & 63 & 13 & 25 & NA & 62.4 & 71.6 & 82.9 & 32 & 6 & 63 \\
\hline Wong HF et al.2007 & Singapore & 181 & 142 & 39 & 0 & NA & 78.5 & NA & 78.5 & 4 & 35 & 142 \\
\hline Tempfer CB et al.2007 & Austria & 96 & 69 & 4 & 23 & NA & 71.9 & 75 & 94.5 & 27 & 0 & 69 \\
\hline Kayikcioglu F et al.2000 & Turkey & 33 & 23 & 7 & 3 & NA & 69.7 & 88.5 & 76.7 & 7 & 3 & 23 \\
\hline Houck K et al.2000 & USA & 140 & 84 & 10 & 46 & NA & 60 & 64.6 & 89.4 & 41 & 15 & 84 \\
\hline Menzin AW et al.1995 & USA & 48 & 23 & 16 & 9 & NA & 47.9 & 71.9 & 46.9 & 22 & 3 & 23 \\
\hline current study.2017 & China & 155 & 127 & 18 & 10 & NA & 81.9 & 92.7 & 87.6 & 22 & 6 & 127 \\
\hline total & & 1577 & 1092 & 254 & 231 & NA & 69.2 & 82.5 & 81.1 & 319 & 166 & 1092 \\
\hline
\end{tabular}

Note: TP: true positive; FP: false positive; TN: true negative; FN: false negative; A: agreement; Sen: sensitivity; Spe: specificity; PPV: positive predictive value; Under: under diagnosis; Over: over diagnosis; Same: same diagnosis; NA: not available.

Table 4. characteristics of included studies for meta-analysis

\begin{tabular}{|c|c|c|c|c|c|c|c|c|c|c|c|c|c|c|c|c|}
\hline \multirow[b]{3}{*}{ studies } & \multicolumn{4}{|c|}{ histology } & \multicolumn{4}{|c|}{ tumor laterality } & \multicolumn{4}{|c|}{ CA-125(U/ml) } & \multicolumn{4}{|c|}{ surgery approach } \\
\hline & \multicolumn{2}{|c|}{$\mathrm{mBOT}$} & \multicolumn{2}{|c|}{ non-mBOT } & \multicolumn{2}{|c|}{ bilateral } & \multicolumn{2}{|c|}{ unilateral } & \multicolumn{2}{|c|}{$\leq 35$} & \multicolumn{2}{|l|}{$>35$} & \multicolumn{2}{|c|}{ Laparotomy } & \multicolumn{2}{|c|}{ laparoscopy } \\
\hline & mis & same & mis & same & mis & same & mis & same & mis & same & mis & same & mis & same & mis & same \\
\hline Halenur B.2016 & 0 & 9 & 8 & 19 & N.A. & N.A. & N.A. & N.A. & 7 & 18 & 1 & 9 & N.A. & N.A. & N.A. & N.A. \\
\hline Basaran D.2014 & N.A. & N.A. & N.A. & N.A. & 4 & 6 & 3 & 31 & 3 & 17 & 4 & 19 & N.A. & N.A. & N.A. & N.A. \\
\hline Song T.2011 & 94 & 123 & 32 & 105 & 5 & 28 & 121 & 200 & N.A. & N.A. & N.A. & N.A. & 103 & 181 & 23 & 47 \\
\hline Shih KK.2011 & 5 & 15 & 11 & 89 & N.A. & N.A. & N.A. & N.A. & N.A. & N.A. & N.A. & N.A. & N.A. & N.A. & N.A. & N.A. \\
\hline Kim JH.2009 & 9 & 42 & 4 & 21 & 1 & 3 & 12 & 60 & 4 & 21 & 7 & 42 & N.A. & N.A. & N.A. & N.A. \\
\hline Houck.2000 & 24 & 23 & 32 & 61 & 9 & 27 & 47 & 57 & N.A. & N.A. & N.A. & N.A. & N.A. & N.A. & N.A. & N.A. \\
\hline current study & 18 & 59 & 10 & 68 & 5 & 36 & 23 & 91 & 15 & 41 & 13 & 86 & 16 & 99 & 12 & 28 \\
\hline
\end{tabular}

Note: mBOT: mucinous borderline ovarian tumors; non-mBOT: non-mucinous borderline ovarian tumors; mis: misdiagnosis; same: same diagnosis; N.A.: not available.

Table 5. The comparison of clinical outcome between misdiagnosis and same-diagnosis group $(n=155)$

\begin{tabular}{|c|c|c|c|c|}
\hline variables & Under Diagnosis $(n=22)$ & Over Diagnosis $(n=6)$ & Same diagnosis $(n=127)$ & $p^{*}$ \\
\hline Chemotherapy & & & & 0.065 \\
\hline Yes & 3 & 2 & 9 & \\
\hline No & 19 & 4 & 118 & \\
\hline Extent of surgery & & & & 0.838 \\
\hline conservative & 12 & 4 & 69 & \\
\hline radical & 10 & 2 & 58 & \\
\hline Recurrence & & & & 0.586 \\
\hline Yes & 2 & 0 & 6 & \\
\hline No & 20 & 6 & 121 & \\
\hline Re-operation & & & & 0.895 \\
\hline Yes & 0 & 0 & 1 & \\
\hline No & 22 & 6 & 126 & \\
\hline Fertility & & & & 0.560 \\
\hline Yes & 1 & 0 & 12 & \\
\hline No & 21 & 6 & 115 & \\
\hline Death & & & & 0.362 \\
\hline Yes & 2 & 0 & 4 & \\
\hline No & 20 & 6 & 123 & \\
\hline
\end{tabular}

Note: * examined by chi-square test, $p$ value less than 0.05 was considered statistically significant 
A

\begin{tabular}{rrrrrr}
\multicolumn{1}{c}{ mucinous } & \multicolumn{3}{c}{ non-mucinous } & \multicolumn{2}{c}{ Odds Ratio } \\
Events & Total & Events & Total & Weight & M-H. Fixed, 95\% C \\
18 & 77 & 10 & 78 & $14.7 \%$ & $2.07[0.89,4.84]$ \\
0 & 9 & 8 & 27 & $8.2 \%$ & $0.12[0.01,2.32]$ \\
24 & 47 & 32 & 93 & $20.3 \%$ & $1.99[0.97,4.06]$ \\
5 & 20 & 11 & 100 & $5.3 \%$ & $2.70[0.82,8.87]$ \\
9 & 51 & 4 & 25 & $8.5 \%$ & $1.13[0.31,4.08]$ \\
94 & 217 & 32 & 137 & $42.9 \%$ & $2.51[1.55,4.05]$ \\
& & & & & \\
& 421 & & 460 & $100.0 \%$ & $2.03[1.47,2.81]$
\end{tabular}

Total events 150 97

Heterogeneity: $\mathrm{Ch}^{2}=5.27, \mathrm{df}=5(\mathrm{P}=0.38) ; \mathrm{l}^{2}=5 \%$

Test for overall effect: $Z=4.29(P<0.0001)$

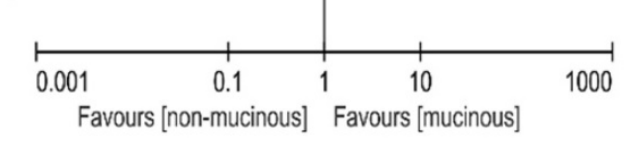

B

\begin{tabular}{|c|c|c|c|c|c|c|c|c|c|c|c|}
\hline Study or Subgroup & $\begin{array}{l}\text { unilater } \\
\text { Events }\end{array}$ & Total & $\begin{array}{l}\text { bilatera } \\
\text { Events }\end{array}$ & & Weight & $\begin{array}{l}\text { Odds Ratio } \\
\text { M-H. Fixed. } 95 \% \mathrm{Cl}\end{array}$ & & $\begin{array}{r}\text { Odds } \\
\text { M-H, Fix }\end{array}$ & $\begin{array}{l}\text { s Ratio } \\
\text { ed. } 95 \% \mathrm{Cl}\end{array}$ & & \\
\hline current study & 23 & 114 & 5 & 41 & $28.7 \%$ & $1.82[0.64,5.16]$ & & & 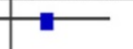 & & \\
\hline D. Basaran et al.2014 & 3 & 34 & 4 & 10 & & Not estimable & & & & & \\
\hline Houck et al.2000 & 47 & 104 & 9 & 36 & $35.9 \%$ & $2.47[1.06,5.77]$ & & & & & \\
\hline Kim JH et al.2009 & 12 & 72 & 1 & 4 & $7.7 \%$ & $0.60[0.06,6.27]$ & & & & & \\
\hline T. Song et al.2011 & 121 & 321 & 5 & 33 & $27.7 \%$ & $3.39[1.27,9.01]$ & & & & & \\
\hline Total $(95 \% \mathrm{Cl})$ & & 611 & & 114 & $100.0 \%$ & $2.39[1.41,4.06]$ & & & & & \\
\hline Total events & 203 & & 20 & & & & & & & & \\
\hline $\begin{array}{l}\text { Heterogeneity: } \mathrm{Chi}^{2}=2 \\
\text { Test for overall effect: } Z\end{array}$ & $\begin{array}{l}9, \mathrm{df}=3( \\
=3.23(\mathrm{P}\end{array}$ & $\begin{array}{l}P=0.5 \\
0.001\end{array}$ & 5); $2^{2}=0 \%$ & & & & 0.01 & $\begin{array}{c}0.1 \\
\text { Favours [bilateral] }\end{array}$ & 1 Favours [u & $\begin{array}{l}10 \\
\text { unilateral] }\end{array}$ & 100 \\
\hline
\end{tabular}

C

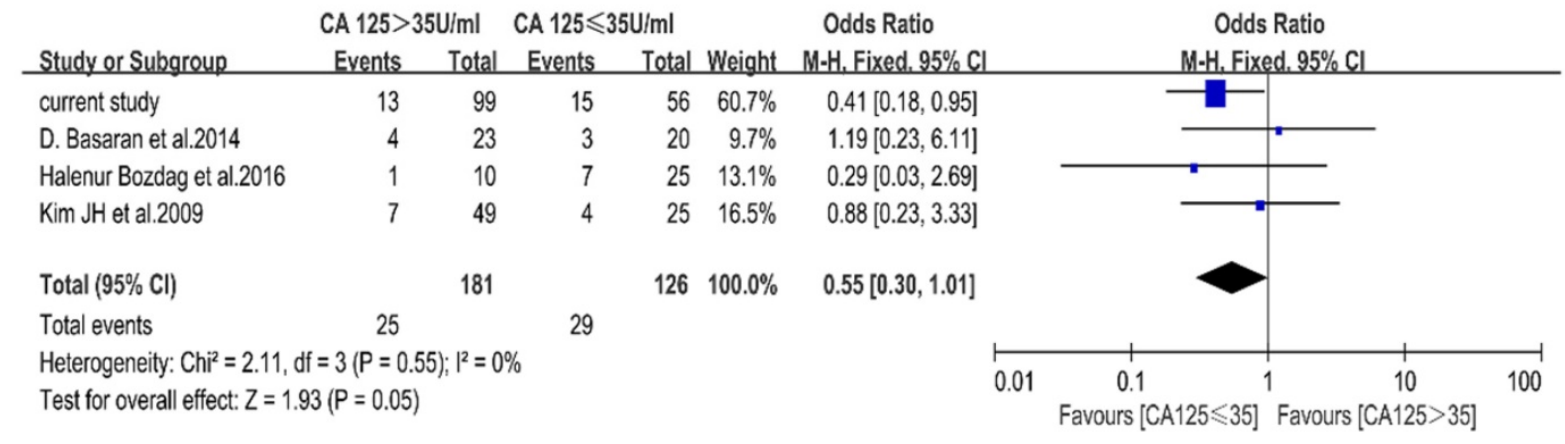

D)

laparoscopy laparotomy Risk Ratio

Study or Subgroup Events Total Events Total Weight M-H. Random. 95\% Cl Year

Risk Ratio

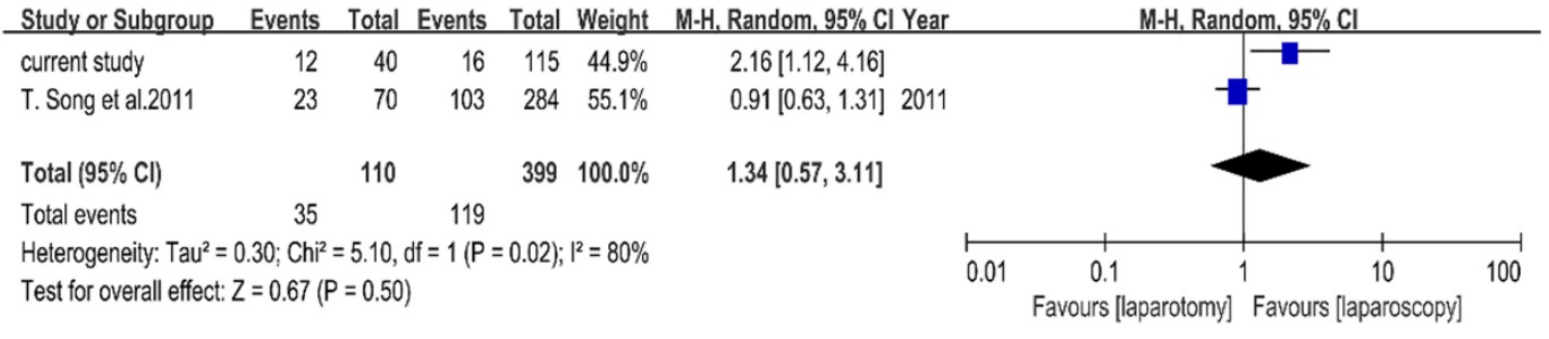

Figure 1. Frost plots evaluating misdiagnosis factors. Notes: the events were defined as misdiagnosed patients of FS, total were defined as the total number of each group. A. Frost plots evaluating mucinous histology. B. Frost plots evaluating tumor laterality. C. Frost plots evaluating CA-125. D. Frost plots evaluating surgery approach. 
There were 28 misdiagnosed cases, including 22 cases which were under-diagnosed and 6 cases which were over-diagnosed. There were specific final diagnoses which were of extreme importance particularly in misdiagnosis cases. In our hospital, the cases of misdiagnosis due to focal carcinoma, micro-papillary and micro-invasion were 17 (60.7\%), $7(25 \%), 4(14.3 \%)$, respectively. In the underdiagnosed group, 15 patients were diagnosed as borderline through FS/malignant through PS. FSS were performed on $8 / 15$ patients, all of whom were under 40 years old; and one patient finished her fertility after surgery. Malignancy recurred in 2/15 patients; one conservative surgery had been performed on one, and radical surgery had been performed on the other, who proved to be at stage FIGO II. Both of them died before the follow-up ended in October 2016. Another 3/15 patients received chemotherapy after surgery, all of whom survived without disease. A total of seven patients were diagnosed as benign through FS/ borderline through PS, four of whom received FSS; none received chemotherapy after surgery. In the over-diagnosed group, three patients were diagnosed as malignant through FS/ borderline through PS, one patient received FSS and had chemotherapy after surgery because of advanced stage of disease and invasive implants. Another patient received chemotherapy because the visible tumor was on the surface of the ovary. Three patients were diagnosed as borderline through FS/ benign through PS, all of whom were less than 40 years old and had FSS. None of them had a recurrence of cancer or death. The comparison of clinical outcomes between misdiagnosed and same diagnosed patients are shown in Table 5. There was no statistical significance of clinical outcome such as extent of surgery $(p=0.838)$, recurrence $(p=0.586)$, fertility $(p=0.560)$, death $(p=0.362)$ between misdiagnosed and accurately diagnosed BOT patients.

\section{Discussion}

The accuracy of diagnosis through FS for BOTs varies among different studies. To assess the reliability of FS diagnosis of BOTs more precisely, we performed a retrospective study as well as a meta-analysis based on available published literature. In this paper, we examined the accuracy of FS diagnosis for BOTs in a large case series, with a total of 1,577 patients enrolled. We concluded that FS analysis of BOTs has a low accuracy, sensitivity, and PPV, also under-diagnosis and over-diagnosis occur frequently.

The sensitivity and PPV in our study were relatively high among the included studies. In most studies, each specimen had one or two [12, 13], at least two [9], or one to seven [14] representative sections sampled for FS after gross inspection, and a minimum of one section per one centimeter of maximal tumor diameter was examined for PS [14, 32]. In our hospital, the number of frozen sections of mBOT, sBOT and other type BOT were 3.21, 3.27 and 3.11 sections respectively. The average number of performed FSs was 3.2 sections. Section were added if there were questionable lesions. There was no statistical significance of frozen section numbers for diagnosis accuracy between different histological type of BOT [36]. On the contrary, some literatures support this view of the number of FS possibly being a factor affecting the rate of accuracy [21, 26, 37].

Improper treatment will follow based on the misdiagnosis of FS. Especially for those young women who still want to preserve their fertility, we should make surgical decisions much more carefully. To improve the accuracy of FS in BOT patients and guide clinical treatment, we also aimed to explore the factors affecting diagnosis accuracy by FS of BOT patients. In our retrospective study, we determined that surgery approach and tumor size were associated with misdiagnosis of FS. To the authors' knowledge, this is the first study to claim that surgery approach is conducive to misdiagnosis of BOTs through FS. Few reports have focused on the effect of surgery approach on diagnosis using FS. Another retrospective study including 354 patients concluded that laparotomy vs. laparoscopy was not statistically significant in the FS diagnosis of BOT, which does not agree with our conclusion, so we performed a meta-analysis to further validate it. In the random model, laparotomy vs. laparoscopy was not associated with misdiagnosis of FS. The discrepant results between our retrospective study and the meta-analysis may originate from the smaller study and the obvious difference of total patients in the two studies (155 vs. 354). Nevertheless, we should also attach importance on this point. Concerns about misdiagnosis with respect to implementing laparoscopy for BOTs include cyst rupture during surgery and residual lesions. According to Fauvet et al. [38]and Oh et al. [39], tumor rupture and incomplete staging were more common when using laparoscopy to resect BOTs. Currently, it is still difficult to make definitive conclusions on this matter due to the lack of clinical studies, but it reminds us that a skilled oncology specialist with sufficient experience would be most desirable when performing laparoscopic surgery on BOT patients.

The outcome of our meta-analysis shows that mucinous histology and unilateral side are related to diagnosis using FS, excluding serum CA125. The 
influence of the mucinous type has often been reported $[6,20,26,40,41]$. This could be explained by the characteristics of mucinous tumors, which are commonly larger than serous tumors and contain benign, borderline, and malignant components together [28,40]. Regrettably, mucinous histology lacked statistical significance in our retrospective study, but the $p$ value was nearly 0.05 .

Our meta-analysis found that based on the random-effect model, unilateral vs. bilateral tumors are not related with misdiagnosis. However, we find that D.Basaran's study has an important influence on the heterogeneity. When this study is excluded, the $\mathrm{I}^{2}$ reduces obviously. We think this originates from the high misdiagnosis rate of $40 \%$ of bilateral BOTs and small sample of 44 cases in D. Basaran's study. Actually, there are 59 discrepancies in that study, but the author included just 44 cases who were diagnosed as having BOT through FS. The analysis method was different from other studies, which we think it is a major reason for the heterogeneity; therefore, we removed it from the meta-analysis of tumor laterality and concluded that unilateral tumors are related to the misdiagnosis using FS. Even though our findings through our retrospective study were different from our meta-analysis results, similar results were seen in some other studies; unilateral tumors were significantly more likely to be under-diagnosed [9, 42].

It was not accessible for us to perform a meta-analysis on tumor size due to the cutoff values varying from report-to-report (i.e. 8, 10, 15 and $20 \mathrm{~cm}$ ). Several studies agree that large tumor size is related to misdiagnosis $[14,25,26,40]$. In a study of 101 patients, Kim JH stated that tumor diameter $>20 \mathrm{~cm}$ was the only factor associated with under-diagnosis [14]. Large masses may have only small foci of invasion in a background of predominantly borderline tumors, which may not be sampled by FS, resulting in reclassification on final pathology [10].

We also focused on the clinical outcomes of BOT patients that stem from misdiagnosis of FS, because there are few reports on this aspect. In a study including 61 patients with under-diagnosis, Kim K stated that the clinical outcome of under-diagnosis by FS examination is minimal in BOTs [33]. Furthermore, Kim $\mathrm{JH}$ found that among 8 under-diagnosed patients, no patient relapsed [14]. They both approve that the clinical outcome of misdiagnosed BOT patients was considerable. We can't treat these misdiagnoses lightly because a small simple size of few related studies had good prognosis. From a long time of follow-up (range10-130 months) of our retrospective study, we verified that clinical impacts of misdiagnosis by FS are minimal in BOT patients, which is in agreement with previous studies [14, 33, 43]. Kim $\mathrm{K}$ stated that under-diagnosis was associated with the extent of surgery, but not associated with treatment failure [33]; however, in our retrospective study, there was no statistical significance between extent of surgery and misdiagnosis. There were $60.7 \%$ $(n=17 / 28)$ patients younger than 40 years old who were misdiagnosed by FS, and $15 / 17$ patients received fertility-sparing surgery. Not only the FS diagnosis, but also the patient's desire to preserve fertility, would affect a surgeon's decision. It is widely believed that most BOT patients have a good prognosis, but a minority will have a more aggressive form of cancer and eventually die from their disease [1].

Pathologists are more likely to use uncertain terms on the FS diagnosis, such as "not excluded" and "not ruled out", which is confusing to surgeons to make a proper surgery decision intra-operatively. In our study, there were 14 patients reported in this way, of which 11 patients proved to have BOT, and 3 patients eventually were diagnosed with malignancies. Only 2/11 patients were performed FSS, and the other 12 patients had radical surgery. Probably the fact that most patients $(8 / 14)$ were more than 40 years old and did not desire fertility explains the excessive surgery outcome, but uncertain FS diagnosis impacted the treatment for patients to some extent. It is crucial for surgeons to communicate well with pathologists to help them, offering important clinical characteristics and intra-operative information such as the tumor size, tumor laterality, and surgery approach. It is also essential for surgeons to understand the meaning of specific terms used in FS reports to properly approach the surgical management of BOTs. It is also a reasonable option to postpone definitive surgical management of BOTs until a final histological report is available.

This study had some limitations as follows. First, this is a retrospective analysis of a single-center cohort of patients with BOTs. Second, heterogeneity regarding the diagnostic criteria of BOTs may exist, due to the large span of time and areas covered by the studies included in this pooled analysis. The strength of this study is that we have increased the sample size to verify previous findings. Furthermore, this is the first meta-analysis focusing on the misdiagnosis risks. Furthermore, we have a long-time follow-up of BOT patients, which offers important information for assessing the clinical outcomes of misdiagnosed patients.

In conclusion, our study demonstrates that FS analysis of BOTs has low accuracy, sensitivity, and PPV. Our meta-analysis validates that mucinous histology and unilateral tumors are associated with 
misdiagnosis of BOTs using FS. We state that laparoscopic surgery would increase the misdiagnosis risk for the first time. And the misdiagnosed patients have good clinical outcomes.

\section{Acknowledgements}

The authors thank Professor XiaoFang Zhang for her assistance and advice on pathology.

\section{Competing Interests}

The authors have declared that no competing interest exists.

\section{References}

1. Fischerova D, Zikan M, Dundr P, et al. Diagnosis, treatment, and follow-up of borderline ovarian tumors. The oncologist. 2012;17(12):1515-1533.

2. Gershenson DM. Management of borderline ovarian tumours. Best Pract Res Clin Obstet Gynaecol. 2017;41:49-59.

3. Abudukadeer A, Azam S, Zunong B, et al. Accuracy of intra-operative frozen section and its role in the diagnostic evaluation of ovarian tumors. Eur J Gynaecol Oncol. 2016;37(2):216-220.

4. Khan AH, Mamoon N, Usman M, et al. Accuracy of intra-operative frozen section in the diagnosis of female genital tract neoplasms. J Pak Med Assoc.2016;66(2):143-146

5. Solmaz Hasdemir P, Guvena T. Borderline ovarian tumors" A contemporary review of clinicopathological characteristics, diagnostic methods and therapeutic options. J BUON. 2016;21(4):780-786.

6. Ayhan A, Ozler A, Dursun P, et al. Potential role of increasing number of sections in frozen section diagnosis of ovarian tumors. J Exp Ther Oncol. 2016; 11(4):245-250.

7. Yarandi F, Eftekhar Z, Izadi MN, et al. Accuracy of intraoperative frozen section in the diagnosis of ovarian tumors. Aust $\mathrm{N} \mathrm{Z} \mathrm{J} \mathrm{Obstet}$ Gynaecol.2008;48(4):438-441.

8. Storms AA, Sukumvanich P, Monaco SE, et al. Mucinous tumors of the ovary: diagnostic challenges at frozen section and clinical implications. Gynecol Oncol. 2012;125(1):75-79.

9. Song T, Choi $\mathrm{CH}$, Kim HJ, et al. Accuracy of frozen section diagnosis of borderline ovarian tumors. Gynecol Oncol. 2011;122(1):127-131.

10. Shih KK, Garg K, Soslow RA, et al. Accuracy of frozen section diagnosis of ovarian borderline tumor. Gynecol Oncol. 2011:123(3):517-521.

11. Basaran D, Salman MC, Calis P, et al. Diagnostic accuracy of intraoperative consultation (frozen section) in borderline ovarian tumours and factors associated with misdiagnosis. J Obstet Gynaecol. 2014;34(5):429-234.

12. Tempfer CB, Polterauer S, Bentz EK, et al. Accuracy of intraoperative frozen section analysis in borderline tumors of the ovary: a retrospective analysis of 96 cases and review of the literature. Gynecol Oncol. 2007;107(2):248-252.

13. Karen $\mathrm{H}$, Najmosama N, Linda $\mathrm{D}$, et al. Borderline tumors of the ovary: correlation of frozen and permanent histopathologic diagnosis. Obstet Gynecol.2000;95(6): 839-843.

14. Kim JH, Kim TJ, Park YG, et al. Clinical analysis of intra-operative frozen section proven borderline tumors of the ovary. J Gynecol Oncol. 2009:20(3):176-180

15. Bozdag H, Guzin K, Gocmen A, et al. The diagnostic value of frozen section for borderline ovarian tumours. J Obstet Gynaecol. 2016;36(5):626-630.

16. Li M, Liu YH, Zhuang HG, et al. Analysis of diagnosis accuracy by frozen sections in 73 cases of borderline tumor of ovary. Chin J Pathology. 2009;38(2):106-109.

17. Rose PG, Rubin RB, Nelson BE, et al. Accuracy of frozen-section (intraoperative consultation) diagnosis of ovarian tumors. Am J Obstet Gynecol. 1994;171(3):823-826.

18. Hashmi AA, Naz S, Edhi MM, et al. Accuracy of intraoperative frozen section for the evaluation of ovarian neoplasms: an institutional experience. World J Surg Oncol. 2016;14:91

19. Cross PA, Naik R, Patel A, et al. Intra-operative frozen section analysis for suspected early-stage ovarian cancer: 11 years of Gateshead Cancer Centre experience. BJOG. 2012;119(2):194-201

20. Brun JL, Cortez A, Rouzier R, et al. Factors influencing the use and accuracy of frozen section diagnosis of epithelial ovarian tumors. Am J Obstet Gynecol. 2008;199(3):244 e1-7.

21. Pongsuvareeyakul T, Khunamornpong S, Settakorn J, et al. Accuracy of frozen-section diagnosis of ovarian mucinous tumors. Int J Gynecol Cance. 2012;22(3):400-406.

22. Morton R, Anderson L, Carter J, et al. Intraoperative Frozen Section of Ovarian Tumors: A 6-Year Review of Performance and Potential Pitfalls in an Australian Tertiary Referral Center. Int J Gynecol Cance. 2017;27(1):17-21.
23. Sukumaran $\mathrm{R}$, Somanathan $\mathrm{T}$, Mathews $\mathrm{A}$, et al. Role of frozen section in intraoperative assessment of ovarian masses: a tertiary oncology center experience. Indian J Surg Oncol. 2014;5(2):99-103.

24. Malipatil R, Crasta JA. How accurate is intraoperative frozen section in the diagnosis of ovarian tumors. J Obstet Gynaecol Res. 2013;39(3):710-713.

25. Geomini PM, Zuurendonk LD, Bremer GL, et al. The impact of size of the adnexal mass on the accuracy of frozen section diagnosis. Gynecol Oncol. 2005;99(2):362-366

26. Tangiitgamol S, Jesadapatrakul S, Manusirivithaya S, et al. Accuracy of frozen section in diagnosis of ovarian mass Source. Int J Gynecol Cancer.2004;14: 212-219.

27. Pinto PB, Andrade LA, Derchain SF. Accuracy of intraoperative frozen section diagnosis of ovarian tumors. Gynecol Oncol. 2001;81(2):230-232.

28. Gol M, Baloglu M, Yigit $S$, et al. Accuracy of frozen section diagnosis in ovarian tumors: Is there a change in the course of time? Int J Gynecol Cancer. 2003; 13:593-597.

29. Larry P, Edward H, James EH, et al. The accuracy of frozen section by tumor weight for ovarian epithelial neoplasms. Gynecol Oncol. 1997; 67:16-19.

30. Colin JR, Barbara AB, Ian GH, et al. Intraoperative assessment of ovarian tumors: a 5-year review with assessment of discrepant diagnostic cases. Int J Gynecol Pathol. 2006;25(4):366-372.

31. Bige $\mathrm{O}$, Demir A, Saygili $U$, et al. Frozen section diagnoses of 578 ovarian tumors made by pathologists with and without expertise on gynecologic pathology. Gynecol Oncol. 2011;123(1):43-46.

32. Andrew WM, Stephen CR, Joel SN, et al. The accuracy of a frozen section diagnosis of borderline ovarian malignancy. Gynecol Oncol. 1995; 59:183-185.

33. Kim K, Chung HH, Kim JW, et al. Clinical impact of under-diagnosis by frozen section examination is minimal in borderline ovarian tumors. Eur J Surg Oncol. 2009;35:969-973.

34. Kayıkçıog F, Tulunaya l, Kösea N. Accuracy of frozen section diagnosis in borderline ovarian malignancy. Gynecol Obstet Invest. 2000; 49:187-189.

35. Wong HF, Low JJ, Chua Y, et al. Ovarian tumors of borderline malignancy: a review of 247 patients from 1991 to 2004. Int J Gynecol Cancer. 2007;17: 342-349.

36. Ayhan A, Ozler A, Dursun $\mathrm{P}$, et al. Potential role of increasing number of sections in frozen section diagnosis of ovarian tumors. J Exp Ther Oncol. 2016;11:245-250.

37. Kuo GW, Tze C, Tao W, et al. Accuracy of Frozen Section Diagnosis in Gynecology. Gynecol Oncol. 1998; 70:105-110.

38. Fauvet R, Boccara J, Dufournet C, et al. Laparoscopic management of borderline ovarian tumors: results of a French multicenter study. Ann Oncol. 2005;16(3):403-410.

39. Oh S, Kim R, Lee YK, et al. Clinicopathological aspects of patients with recurrence of borderline ovarian tumors. Obstet Gynecol Sci. 2015;58(2):98-105.

40. Moroney MR, Post MD, Berning AA, et al. An Evaluation of Frozen Section and Lymph Node Dissection Results for Mucinous Ovarian Tumors. Int J Gynecol Cancer. 2018;28:92-98.

41. Shah J, Mackelvie M, Gershenson DM, et al. Accuracy of Intraoperative Frozen Section Diagnosis of Borderline Ovarian Tumors by Hospital Type. J Minim Invasive Gynecol 2018; [Epub ahead of print].

42. Houck K, Nikrui N, Duska L, et al. Borderline tumors of the ovary: correlation of frozen and permanent histopathologic diagnosis. Obstet Gynecol.2000;95(6): 839-843.

43. Koensgen $\mathrm{D}$, Weiss $\mathrm{M}$, Assmann $\mathrm{K}$, et al Characterization and management of borderline ovarian tumors - results of a retrospective, single-center study of patients treated at the department of gynecology and obstetrics of the university medicine Greifswald. Anticancer Res. 2018;38:1539-1545. 